\title{
Source of group B streptococci in the female genital tract
}

\author{
PJ SANDERSON,1 JEAN ROSS,1 AND JACQUELINE STRINGER ${ }^{2}$ \\ From the ${ }^{1}$ Northwick Park Hospital and Clinical Research Centre, Watford Road, Harrow, Middlesex \\ HA1 3UJ, and ${ }^{2}$ Division of Hospital Infection, Central Public Health Laboratories, Colindale Avenue, \\ London NW9 5HT, UK
}

SUMmARY Swabs were taken from the posterior fornix, perineum, and anorectum of 135 patients on three occasions during their pregnancy. Multiple isolates of $\beta$-haemolytic streptococci of group B were obtained from 24 women, in 21 of whom the strains were examined by a highly discriminative serotyping and phage typing method. In 18 of these patients their own isolates were indistinguishable but different from those of other women with multiple isolates. Women yielding group B streptococci from the posterior fornix usually carried an indistinguishable strain in the anorectum.

Haemolytic streptococci of Lancefield's group B are an important and possibly increasing cause of neonatal morbidity and death..$^{1-3}$ Neonatal colonisation usually arises from the mother's genital tract. ${ }^{4}$ In this study we have used a highly discriminative serological and bacteriophage typing $\operatorname{method}^{6}$ to examine the similarity or otherwise of strains of group B streptococci obtained from the vagina, perineum, and anorectum of pregnant women in an attempt to gather evidence for the source of this organism in the female genital tract.

\section{Patients and methods}

The 135 patients studied were randomly selected from the women attending the antenatal clinics of Northwick Park Hospital. Swabs were obtained from their posterior fornix, perineum, and anorectum at 16,28 , and 36 weeks of pregnancy. In some patients the skin of the anterior axillary fold and the mucosa of the urethra were also swabbed. The perineum and axilla were sampled by cottonwool swabs moistened in peptone water, the urethra by a narrow-gauge soft-wire swab, and the posterior fornix and anorectum by charcoal-impregnated swabs. Swabs were immediately broken off into $10 \mathrm{ml}$ Todd Hewitt broth containing $8 \mu \mathrm{g} / \mathrm{ml}$ gentamicin and $15 \mu \mathrm{g} / \mathrm{ml}$ nalidixic acid and the broth incubated at $37^{\circ} \mathrm{C} .7^{8}$ Subcultures were made on to Columbia blood agar and incubated aerobically. Isolates resembling group B streptococci which were able to grow on $40 \%$ bile agar and failed to hydro-

Accepted for publication 23 June 1980 lyse aesculin were grouped by slide agglutination, serotyped by precipitation tests in gel, and phage typed by the technique described by Stringer and Maxted. ${ }^{6}$

\section{Results}

Thirty $(22 \%)$ of the 135 women yielded group B streptococci from the anorectum on one or more occasions. In eight of these 30 the organism was isolated only from the anorectum: in the remaining 22 the organism was also found at other sites. In two women the organism was recovered from the posterior fornix and in one from the perineum without recovery from the anorectum.

The Table shows the sites from which the 104

Pattern of recovery of group B streptococci from 'sets' of three swabs in 135 women during pregnancy

\begin{tabular}{llll}
\hline $\begin{array}{l}\text { Posterior } \\
\text { fornix }\end{array}$ & Perineum & Anorectum & $\begin{array}{l}\text { No. of 'sets'* of swabs yielding group } \\
\text { B streptococci from sites indicated } \\
\text { (+ recovery, O no recovery) }\end{array}$ \\
\hline 0 & & & 26 \\
0 & + & + & 3 \\
+ & 0 & 0 & 7 \\
0 & + & + & 5 \\
+ & 0 & + & 12 \\
+ & + & 0 & 2 \\
+ & + & + & 10 \\
0 & 0 & 0 & 340
\end{tabular}

No. of sets of swabs (total swabs) 405 (1215)

No. of sets of swabs yielding group B streptococci

65

*A 'set' of 3 swabs comprised swabs from the posterior fornix, perineum, and anorectum from one patient on one occasion. 
isolates of group B streptococci were recovered. In 53 out of 65 positive 'sets' of swabs (a 'set' equals swabs from the posterior fornix, perineum, and anorectum from one patient on one occasion) an isolate was obtained from the anorectum. The skin of the anterior axillary fold of 72 women was swabbed on three occasions during their pregnancies without recovery of group B streptococci. One out of 42 urethral swabs yielded the organism.

Twenty-four women yielded two or more isolates of group B streptococci at different times or from multiple sites, or both, during their pregnancy. The multiple isolates from 21 of these women were available for comparison (both with themselves and with those of other women) by serotyping and phage typing. In 18 out of the 21 women their multiple strains were shown to be indistinguishable between themselves, but the isolates from each woman showed a different phage pattern from those of other women in the study. Two women yielded strains that were not phage typable but were of the same serotype. The isolates from the remaining woman showed a difference in phage pattern and a corresponding difference in serotyping. The isolates from three women showed minor variation in serotype but not in phage type.

\section{Discussion}

The combination of serotyping and phage typing of group B streptococci is highly discriminative ${ }^{6}$ and showed in this study that a single strain of the organism can widely colonise the anogenital area of pregnant women over a period of months.

Group B streptococci were recovered from the anorectum more often than from the posterior fornix or perineum, as other workers have found. 4910 This suggests that the anorectum or bowel is the natural habitat of group B streptococci. If that is the case it is likely that the perineum, vagina, and urethral orifice may be colonised from this source, in view of the apparent identity of the strains recovered during this study from multiple sites in the genital area. The source of group B streptococci in the anorectum itself may be from faeces. Unsworth ${ }^{11}$ recovered these organisms from two out of 12 samples of faeces. Unfortunately there are no reports of the recovery of group B streptococci from samples of stool obtained by methods that avoid contamination from the anorectum.

Our study has shown that isolates recovered in pregnant women from the posterior fornix and perineum were indistinguishable from those obtained from the anorectum, which may indicate that group B streptococci colonise the genital area of women from this site. Alternatively they may pass between one site or the other or colonise the entire genital area including the anorectum. Group B streptococci were obtained from the skin of the perineum in $15 \%$ of our patients but never from the axilla. Possibly these organisms pass to the vagina over the perineum from the anorectum, just as organisms found in urinary tract infection may follow the same route to the bladder. ${ }^{12}{ }^{13}$ Interestingly, the strains recovered from single patients were usually distinguishable from those of other women. In a population of 206 epidemiologically independent strains from one hospital Stringer and Maxted $^{14}$ recognised 98 different serophage 'types'. The percentage of the most common 'type' was 6.3 but few others exceeded $3.0 \%$.

We found only one out of 42 urethral swabs positive, although higher rates of recovery from this site have been reported..$^{15}$ When swabs of the urethra are taken, however, contamination of the swab by organisms from the urethral orifice is difficult to avoid. A higher isolation rate of group B streptococci has been reported from the periurethra than from the urethra ${ }^{16}$ when these sites were compared. This finding must throw doubt on the real source of the organisms obtained from the urethral mucosa.

The failure of antibiotics to eliminate carriage of group B streptococci in the female genital tract ${ }^{17} 18$ is explained if their source lies in the anorectum or bowel, where systemic antibiotics are unlikely to penetrate and from which colonisation of the genital tract may occur. In view of the wide colonisation of the female genital area with group B streptococci and of the importance of the anorectum as the probable source of the organisms, local antiseptic should be applied widely to the anogenital area, including the anorectum, during delivery. ${ }^{19}$

We thank the obstetricians of Northwick Park Hospital for allowing us to study their patients, Dr KB Rogers for helpful discussions, Heather Anderson and Latika Shah for expert technical work, and Sandra Kerr for typing the manuscript. Part of the work was supported by a grant from the North-West Thames Regional Research Committee.

\section{References}

${ }^{1}$ Eickhoff TC, Klein JO, Daly AD, et al. Neonatal sepsis and other infections due to group B beta-haemolytic streptococci. N Engl J Med 1964;271:1221-8.

2 Reid TMS. Emergence of group B streptococci in obstetric and perinatal infections. $\mathrm{Br}$ Med J 1975 ; : :533-5.

${ }^{3}$ Baker CJ. Summary of the workshop on perinatal infections due to group B streptococcus. J Infect Dis 1977; 136:137-52.

4 Franciosi RA, Knostman JD, Zimmerman R. Group B streptococcal neonatal and infant infections. $J$ Paediatr $1973 ; 82: 707-18$. 
${ }^{5}$ Baker CJ, Barrett FF. Transmission of group B streptococci among parturient women and their neonates. $J$ Paediatr 1973;83:919-25.

${ }^{6}$ Stringer Jacqueline, Maxted WR. Phage typing of group B streptococci. Lancet 1979;1:328.

${ }^{7}$ Baker CJ, Clark DJ, Barrett FF. Selective broth medium for the isolation of group B streptococci. Appl Microbiol 1973;26:884-5.

${ }^{8}$ Mason EO, Wong P, Barrett FF. Evaluation of four methods for detection of group B streptococcal colonisation. J Clin Microbiol 1976;4:429-31.

${ }^{9}$ Badri MS, Zawaneh S, Cruz AC, et al. Rectal colonisation with group B streptococcus: relation to vaginal colonisation of pregnant women. J Infect Dis 1977;135:308-12.

${ }^{10}$ Patterson MJ, Hafeez AEB. Group B streptococci in human disease. Bacteriol Rev 1976;40:774-92.

${ }^{11}$ Unsworth PF. Streptococci in human faeces. In: Parker MT, ed. Pathogenic Streptococci. Chertsey: Reedbooks, 1979:239.

${ }^{12}$ Stamey TA, Timothy M, Miller M, et al. Recurrent urinary enterobacteria. California Medicine 1971;115:1-19.

${ }^{13}$ Grüneberg RN. Relation of infecting urinary organisms to the rectal flora in patients with symptomatic urinary infection, Lancet 1969 ;ii:766-8.
"Stringer Jacqueline, Maxted WR. Epidemiological evaluation of a phage typing system for group B streptococci. In: Parker MT, ed. Pathogenic Streptococci. Chertsey: Reedbooks, 1979:262.

${ }^{15}$ Christensen KK, Christensen P, Juldorf F, Pettersson L. Rectal colonisation with group B streptococci: relation to urogenital carriage. Scand J Infect Dis 1978;10:291-3.

${ }^{16}$ Bollgren I, Vaclavinkova V, Hurvell B, Bergqvist G. Periurethral aerobic microflora of pregnant and nonpregnant women. Br Med J 1978;1:1314-7.

17 Paredes A, Wong P, Mason EO, Yow MD. Failure of penicillin to eradicate the carrier state of group B streptococci. Clin Res 1976;24:71 A.

${ }_{18}$ Hall HT, Barnes W, Krishnan L, et al. Antibiotic treatment of parturient women colonised with group B streptococci. Am J Obstet Gynecol 1976;124:630-4.

19 Parker MT. Neonatal streptococcal infections. Postgrad Med J 1977;:53:598-606.

Requests for reprints to: Dr PJ Sanderson, Edgware General Hospital, Edgware, Middlesex. 